\title{
¿EMPATÍA O CÁLCULO? UN ANÁLISIS CRÍTICO DE LA GEOPOLÍTICA DE LAS VACUNAS EN AMÉRICA LATINA
}

\author{
EMPATHY OR CALCULATION? A CRITICAL ANALYSIS OF \\ VACCINATION GEOPOLITICS IN LATIN AMERICA
}

\section{EMPATHIE OU CALCUL? UNE ANÁLYSE CRITIQUE DE LA GÉOPOLITIQUE DE VACCINS EN AMÉRIQUE LATINE}

\author{
Bernabé Malacalza \\ Universidad Nacional \\ de Quilmes, Conicet, \\ b.malacalza@conicet.gov.ar \\ Debora Fagaburu \\ Universidad Nacional \\ de Quilmes, Conicet, \\ deborafagaburu@gmail.com
}

Resumen: La geopolítica de las vacunas es un empeño de las potencias productoras caracterizado por la puja por accesos e influencia que acompaña a los acuerdos de exportaciones, de instalación de plantas productoras y de donaciones. La pandemia de Covid-19 ha exacerbado el nacionalismo de vacunas, la disputa entre Estados Unidos-China y las desigualdades de acceso en América Latina. El aporte de este artículo radica en hacer un análisis en profundidad de las estrategias geopolíticas que se verifican en torno a las transacciones de vacunas en la región. Desde la precedencia de lo geopolítico sobre lo sanitario, analizamos, a partir de un estudio de la distribución de transacciones, las preferencias políticas de Estados Unidos y los países europeos, China, India y Rusia. Encontramos dos tipos de influencia: en las estrategias china y rusa prevalecen preferencias políticas ofensivas y defensivas combinadas con diplomacia económica de base; en las de Estados Unidos, Europa e India, las preferencias políticas también son ofensivas-defensivas pero la diplomacia económica es de cúpula.

Palabras clave: ayuda externa; geopolítica de vacunas;

América Latina; Covid-19. 
ABSTRACT: Vaccination geopolitics is an effort by the producer countries characterized by a struggle for access and influence that accompanies the export agreements, setting up of manufacturing plants, and donations. The covid-19 pandemic has exacerbated vaccine nationalism, United States-China clashes and inequality of access in Latin America. This article offers an in-depth analysis of the geopolitical strategies emerging around vaccine transactions in the region. Focusing on the precedence of geopolitical concerns over health ones, we use a study of transaction distribution to analyze the political preferences of the United States and the European countries, China, India and Russia. This points to two kinds of influence: the Chinese and Russian strategies are dominated by offensive and defensive political preferences combined with a ground-up economic diplomacy, while those of the United States, Europe and India are also offensive-defensive, but the economic diplomacy is top-down.

Keywords: external aid; vaccine geopolitics; Latin America; CovID-19.

\section{Traducción de Fionn Petch, cm Idiomas}

Resumé: La géopolitique des vaccins est un effort des puissances productrices caractérisé par les enchères pour des accès et des influences qui accompagnent les accords d'exportation, d'installation d'usines de production et de dons. La pandémie de covid-19 a exacerbé le nationalisme vaccinal, le différend américano-chinois et les inégalités d'accès en Amérique latine. L'apport de cet article réside dans une analyse approfondie des stratégies géopolitiques qui se vérifient autour des transactions concernant les vaccins dans la région. A partir de la primauté du géopolitique sur la santé, nous analysons, basés sur une étude de la répartition des transactions, les préférences politiques des Etats-Unis et des pays européens, la Chine, l'Inde et la Russie. On retrouve deux types d'influence: dans les stratégies chinoises et russes prévalent des préférences politiques offensives et défensives, combinées à une diplomatie économique de base; dans celles des États-Unis, de l'Europe et de l'Inde, les préférences politiques sont également offensives-défensives mais la diplomatie économique est de chapelles. Mots-clés: aide extérieure; géopolitique vaccinale ; Amérique latine ; Covid-19.

\section{Traducción de Rafael Segovia, cm Idiomas}

Fecha de recepción: agosto de 2021

Fecha de aceptación: octubre de 2021 


\section{INTRODUCCIÓN}

- Quiénes y por qué deciden la distribución de vacunas entre países? La pandemia de Covid-19 será recordada, desde el espejo retrovisor del futuro, como un periodo en el que las tendencias al nacionalismo de vacunas y a la desigualdad retomaron fuerza y trascendencia. Los datos sugieren que 27 países y territorios ricos del mundo, que abarcan sólo $10 \%$ de la población mundial, acaparan $32 \%$ de las dosis disponibles en el mundo. ${ }^{1}$ En América Latina, las transacciones de vacunas comenzaron en 2020, pero esto no significó que se hubieran reactivado mecanismos regionales de compra conjunta de vacunas. Hay países como Chile y Uruguay que reportan coberturas de vacunación completa similares a las de Europa y América del Norte, mientras otros, como Jamaica, Nicaragua y Haití, alcanzan porcentajes de vacunación inferiores a $5 \% .^{2}$ A la vez, estas brechas son también reflejo de las fallas del mecanismo multilateral covax, que apenas alcanzó a cubrir la inmunización completa de $1.4 \%$ de la población en la región. ${ }^{3}$ Aquí llegamos a una paradoja que roza lo absurdo: la región salió a negociar el acceso a vacunas sin coordinación y con una insolvencia estratégica que ha sido aprovechada por múltiples actores del exterior -potencias productoras y laboratorios farmacéuticos- en un escenario global cada vez más pugnaz.

${ }^{1}$ Naciones Unidas, UNESCO, “Covid-19 y Vacunación en América Latina y el Caribe: desafío, necesidades y oportunidades", 4 de agosto de 2021, https:// es.unesco.org/news/covid-19-y-vacunacion-america-latinay-caribe-desafios-necesidades-y-oportunidades

${ }^{2}$ Comisión Económica para América Latina (Cepal), "La paradoja de la recuperación en América Latina y el Caribe. Crecimiento con persistentes problemas estructurales: desigualdad, pobreza, poca inversión y baja productividad", Santiago de Chile, Cepal, Informe especial, coviD 19, núm. 11, 8 de julio de 2021,https:/ / repositorio.cepal.org/bitstream/ handle/11362/47043/5/S2100379_es.pdf

${ }^{3}$ Naciones Unidas, UNESCO, art. cit. 
De manera directa e indirecta, hay varias dimensiones -domésticas, regionales y mundiales- que configuran esta realidad; sin embargo, un modo de aproximarse a la cuestión es examinando las estrategias de las principales potencias productoras en el terreno regional de acuerdo con algunos indicadores. El propósito aquí es analizar con mayor atención una de las causas principales de los problemas de acceso a las vacunas en una de las regiones más rezagadas del reparto mundial: la llamada geopolítica de vacunas. ¿Cuáles fueron las preferencias políticas y las estrategias geopolíticas que configuraron las transacciones de vacunas contra COVID-19 de las potencias productoras en la región? ¿Qué asuntos fueron vinculados a través de la geopolítica de vacunas? ¿Qué objetivos económicos persiguieron las potencias productoras y sus laboratorios farmacéuticos?

Para entender la disputa entre las potencias productoras extrarregionales en torno a las vacunas, proponemos asumir una perspectiva geopolítica, entendida ésta como un modo de interpretar el mundo en el que se pone énfasis en la explicación del peso de los factores espaciales. ${ }^{4} \mathrm{La}$ geopolítica de vacunas tiene entonces dos caras: la puja por accesos (a tecnologías, recursos y mercados) e influencia (búsqueda de concesiones políticas y económicas), de un lado, y la denegación de accesos (control sanitario, restricciones y vetos), del otro. Nuestra hipótesis es que las potencias productoras extrarregionales utilizaron las transacciones de vacunas para obtener accesos así como gestionar, mantener y sostener posiciones de influencia política y económica para sus países y sus empresas. Las principales referencias de esa disputa por el control de las cadenas globales de valor tecnointensivas son Estados Unidos y China; sin embargo, cabe observar esa racionalidad respecto a las estrategias de otras

${ }^{4}$ Saul Bernard Cohen, "Geopolitics: the geography of international relations”, Londres, Rowman \& Littlefield, 2014. 
potencias productoras satélites como los países europeos, India y Rusia. ${ }^{5}$

Dedicamos la siguiente sección a abordar el contexto de la producción mundial de vacunas antes y durante la pandemia, poniendo el énfasis en el patrón global de distribución de tecnología vinculada a las vacunas entre países. En la sección subsiguiente, trataremos brevemente los temas que ayudan a completar nuestro análisis sobre la geopolítica de vacunas de las principales potencias productoras mundiales: China, Estados Unidos y los aliados europeos, India y Rusia; lo que denominamos "estrategias geopolíticas", con el propósito de dar cuenta de lógicas más acotadas que han servido de guía a las transacciones de vacunas en la región. Cerraremos el trabajo con una conclusión de naturaleza comparada.

\section{LAS POTENCIAS PRODUCTORAS DE VACUNAS}

La geopolítica de las vacunas tiene como protagonistas a potencias productoras que deciden cómo producir y dónde destinar las vacunas y a qué gobiernos de países compradores o receptores que establecen a quién vacunar y cuándo. Sin embargo, los criterios de asignación dependen en gran medida de la industria farmacéutica que hace los anuncios científicos sobre la eficacia de sus productos, anuncia los plazos, crea las expectativas, impone los precios y exige inmunidad sobre los posibles efectos secundarios negativos de sus vacunas. La resultante es la consolidación de una división jerárquica entre potencias productoras-empresas y países receptores-compradores, cuya frontera se encuentra establecida por el patrón de distribución de tecnologías de producción.

${ }^{5}$ Rajeev Bhutani Brig, "Geopolitics To Geo-Economics To... The New Era of Geo-Technology”, India, Centre for Joint Warfare Studies, 2019, https:/ / cenjows.in/upload_images/pdf/Inside_GEOPOLITICS_10-5-19.pdf 
Siguiendo a Robert Cox, el desarrollo tecnológico no es un proceso que evoluciona en forma lineal y exclusivamente basado en mejoras técnicas, sino que las tecnologías dominantes coexisten con tecnologías anteriores en formas complejas de relaciones jerárquicas que reflejan relaciones de poder. ${ }^{6}$ La internacionalización de la producción determina, entonces, una estructura centro-periferia a escala mundial. Las fases más intensivas en capital de la producción de vacunas y la innovación de las tecnologías más sofisticadas mediante investigación y desarrollo tienen lugar en el centro, mientras que las fases más intensivas en trabajo y tecnologías estandarizadas se mueven hacia la periferia. No cabe duda de que América Latina ocupa la periferia y la semiperiferia de esos encadenamientos, por lo que la geopolítica de vacunas en la región es un espejo de la distribución del poder tecnológico. ${ }^{7}$

¿Cuáles son hoy las potencias productoras? En el contexto actual, aunque los mayores productores de vacunas COVID-19 siguen siendo los mismos países productores de la prepandemia, la segmentación del marcado ha cambiado considerablemente. Entre 2017 y 2019, la Unión Europea fue el principal productor mundial de vacunas y proveedor, junto con Estados Unidos, de los países de ingresos altos; mientras que la India suministró vacunas a los países de ingresos bajos y China produjo casi exclusivamente para su propio mercado. ${ }^{8}$ En ese periodo, la Unión Europea concentró 15.7 millones de kilogramos de la producción mundial; la India, 14.2; China, 10; Estados Unidos, 5, y Rusia apenas 1 (ver gráfica 1). Sin embargo, con la pandemia en curso, China se convirtió en el primer productor global de vacunas contra

${ }^{6}$ Robert Cox, Production, power and world order. Social forces in the making of history, Nueva York, Columbia University Press, 1987.

${ }^{7}$ Loc. cit.

${ }^{8}$ Lionel Guetta-Jeanrenaud, Nicolas Poitiers y Reinhilde Veugelers, "A world divided: global vaccine trade and production", Bruegel [Blog], 20 de julio de 2021, https://www.bruegel.org/2021/07/a-world-dividedglobal-vaccine-trade-and-production/ 
COVID-19 con 597 millones de dosis, seguida de Estados Unidos con 333, la Unión Europea con 319, la India con 249 y Rusia con 35. La resultante es una redistribución del poder tecnológico de vacunas que se refleja en el ascenso relativo bastante marcado de China y de Estados Unidos, a la par de un declive relativo de la Unión Europea y la India, y un leve incremento del peso de Rusia.

\section{CUADro 1}

Mercado global de vacunas prepandemia y de vacunas COVID-19 a mayo de 2021

\begin{tabular}{|l|c|c|c|c|}
\hline & $\begin{array}{c}\text { Rango de } \\
\text { producción } \\
\text { estimado } \\
\text { prepandemia } \\
\text { (millones de kg, } \\
2017-2019)\end{array}$ & $\begin{array}{c}\text { Participación } \\
\text { en exportaciones } \\
\text { de vacunas } \\
\text { prepandemia } \\
\text { (volumen, } \\
2017-2019)\end{array}$ & $\begin{array}{c}\text { Producción } \\
\text { vacunas CovID-19 } \\
\text { para mercado } \\
\text { interno } \\
\text { (millones de dosis) }\end{array}$ & $\begin{array}{c}\text { Exportaciones de } \\
\text { vacunas covID-19 } \\
\text { (millones de } \\
\text { dosis) }\end{array}$ \\
\hline China & 10 & 1.93 & 345 & 252 \\
\hline Estados Unidos & 5 & 15.09 & 330 & 3 \\
\hline Unión Europea & 15,7 & 44.03 & 208 & 111 \\
\hline India & 14,2 & 24.65 & 180 & 69 \\
\hline Rusia & 1 & 0 & 22 & 13 \\
\hline República de & 1 & 3.29 & 3 & 27 \\
Corea & $\mathrm{n} / \mathrm{d}$ & 2.73 & $\mathrm{n} / \mathrm{d}$ & $\mathrm{n} / \mathrm{d}$ \\
\hline Reino Unido & $\mathrm{n} / \mathrm{d}$ & 8.28 & $\mathrm{n} / \mathrm{a}$ & $\mathrm{n} / \mathrm{a}$ \\
\hline Otros & 100 & 1088 & 1188 \\
\hline Total & & & & \\
\hline
\end{tabular}




\section{GráfICA 1}

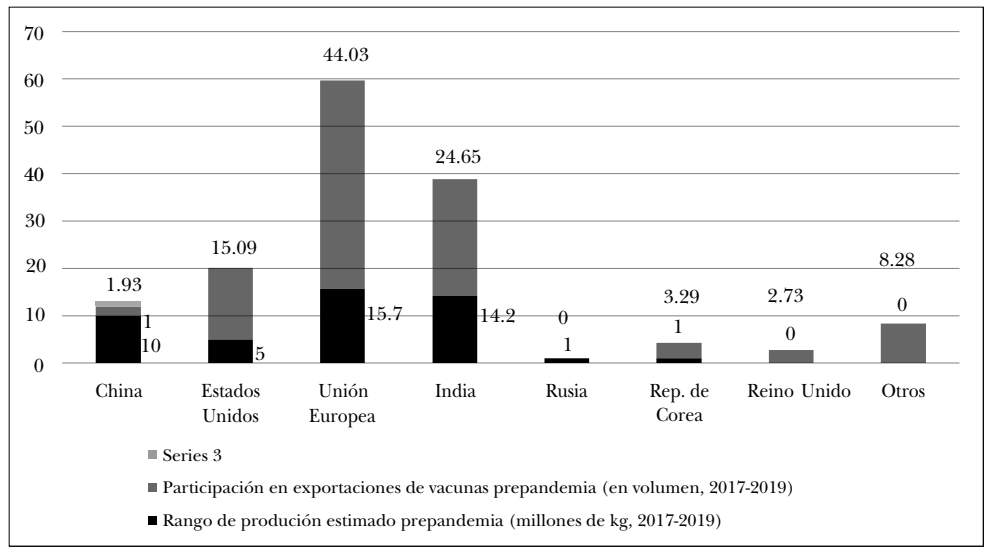

Fuente: elaboración propia con base en Lionel Guetta-Jeanrenaud, Nicolas Poitiers y Reinhilde Veugelers, "A world divided: global vaccine trade and production”, Bruegel [Blog], 20 de julio de 2021, https:/ /www.brue gel.org/ 2021/07/a-world-divided-global-vaccine-trade-and-production/

\section{GRÁfICA 2}

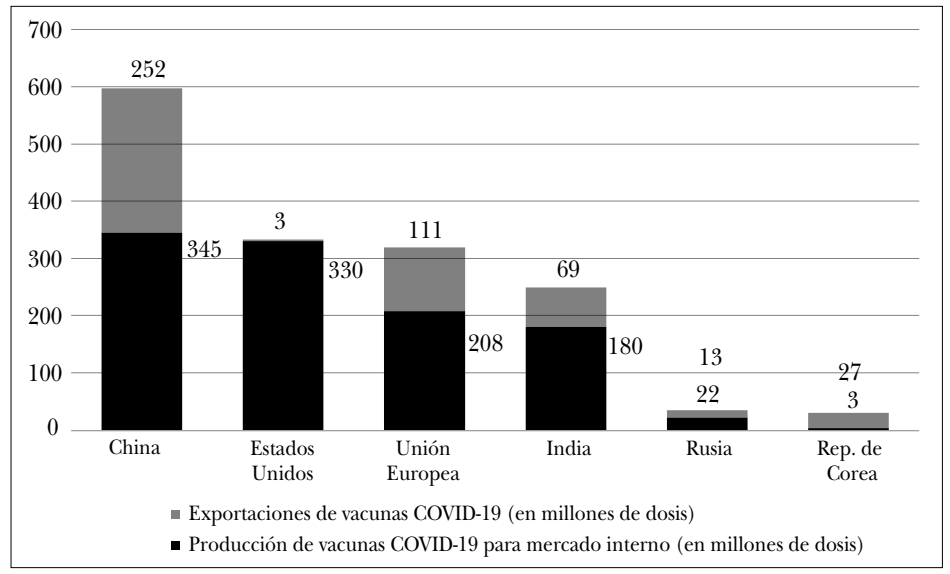

Fuente: elaboración propia con base en Lionel Guetta-Jeanrenaud, Nicolas Poitiers y Reinhilde Veugelers, "A world divided: global vaccine trade and production”, Bruegel [Blog], 20 de julio de 2021, https:/ /www.brue gel.org/ 2021/07/a-world-divided-global-vaccine-trade-and-production/ 
Es posible destacar al menos cinco cambios observables en el contexto pandémico. Primero, el principal rasgo de época es que China y Estados Unidos concentran en pandemia más de la mitad de la capacidad tecnológica global de producción de vacunas contra Covid-19. Segundo, cuatro países -Estados Unidos, China, India y Rusia- y un grupo de países -la Unión Europea-son las principales potencias productoras. Tercero, China se ha convertido en el primer exportador de vacunas COVID-19 y desplazó a la India como proveedor principal de países de ingresos medios y bajos. Cuarto, Europa se encuentra principalmente orientada a su mercado interno, con una leve proyección en sus exportaciones dado el protagonismo de la firma AstraZeneca (Reino Unido/Suecia) además de las contribuciones al mecanismo covax. Por último, Rusia exporta más de lo habitual, pero su peso es aún bastante menor al resto de las potencias productoras en términos de volumen de producción y de exportaciones.

\section{GEOPOLÍTICA DE VACUNAS Y VINCULACióN DE CUESTIONES}

El tema de la geopolítica de vacunas ha ocupado en América Latina un lugar significativo en el debate institucional, partidista y académico. El concepto ha sido visto como simultáneamente peyorativo y ambiguo por aquellos que han mostrado interés en el asunto. Sin embargo, es posible pensar en la existencia de lineamientos y estrategias geopolíticas en el campo de vacunas contra Covid-19. No como un paquete articulado de políticas orientadas a un fin estratégico superior, sino como un instrumento más del principio ordenador de la acción externa de las potencias productoras que sirve a la vinculación de cuestiones tácticas y sustantivas en materia de política exterior.

En este escenario, la geopolítica de vacunas plantea tanto desafíos, al servir como conducto de los intereses de potencias productoras, como oportunidades, al ofrecer espacios de inserción en cadenas de valor a los países de la región. 
Aunque no siempre las expectativas sobre vinculación de cuestiones forman parte de los acuerdos, pueden estar presentes en el desarrollo posterior de las relaciones bilaterales entre las potencias productoras y los países receptores. Las vinculaciones tácticas pueden darse cuando los temas vinculados por una potencia no están relacionados entre sí de una manera coherente, sino que parecen haber sido motivados por los intentos de las potencias de extender su poder dominante de negociación o veto desde un área temática en particular hacia otras. En contraste, las vinculaciones sustantivas resultan de la coherencia de los problemas para expandir un mismo rango temático. ${ }^{9}$ Por ejemplo, ingenieros, científicos, economistas y funcionarios públicos pueden aprovechar las transacciones de vacunas para cubrir temas relacionados, tales como acceso al financiamiento, adquisición de patentes y construcción de fábricas de insumos o medicamentos. Los casos de China, Estados Unidos y los países europeos, India y Rusia son ilustrativos de estas tendencias.

\section{China, el gran ascendente y la apuesta temprana}

Desde su lanzamiento en 2013, y de manera más específica, a partir del desembarco en América Latina con el ingreso de Panamá en 2017, la Iniciativa de la Franja y la Ruta (BRI, por sus siglas en inglés) se ha constituido como la principal plataforma de proyección geopolítica del Estado chino y sus empresas. La BRI configura el sentido de los despliegues geopolíticos de dos maneras: por un lado, es atractiva para los países miembros porque ofrece oportunidades de financiamiento para abordar necesidades reales de infraestructura; por el otro, la influencia económica resultante es también un medio de Beijing para tener acceso a mercados, proyec-

${ }^{9}$ Paul Poast, "Does issue linkage work? Evidence from European alliance negotiations, 1860 to 1945”, International Organization, vol. 66, núm. 2, 2012, pp. 277-310. 
ción de empresas y obtención de concesiones políticas en diversas cuestiones, entre las que resultan fundamentales las garantías de acceso al mercado para tecnologías de última generación. ${ }^{10}$

El objetivo primordial que tiene China de fortalecer esta plataforma en las diferentes regiones del mundo se manifiesta de manera evidente en la geopolítica de las vacunas. El dato elocuente es que, del total de 98 países en los que Beijing desembarcó con 405 millones de dosis, 85 son miembros de la BRI, una proporción equivalente a casi el $90 \%$ del total. ${ }^{11}$ En América Latina, la ecuación no es tan lineal, ya que 10 países miembros de la BRI, de un total regional de 18 adherentes, recibieron vacunas chinas. Uruguay y Chile, los primeros países sudamericanos en ingresar a la BRI en 2018, fueron los que avanzaron de manera más rápida en los procesos de vacunación a partir de la recepción del biológico de la firma privada Sinovac, tras haber sido, en el caso de Chile, lugar de ensayo de ese laboratorio. Posteriormente, ambos países fueron conductos para donar vacunas chinas a Paraguay, país que no reconoce a China y mantiene relaciones diplomáticas con Taiwán.

Es preciso señalar que no sólo las exportaciones fueron fluidas hacia miembros de la BRI, sino que también la política de donaciones se centró en ese destino; así lo reflejan los casos de Venezuela, Guyana, El Salvador, Dominica, Ecuador, Bolivia y República Dominicana (véase el cuadro 3$).{ }^{12}$

${ }^{10}$ Haoguang Liang y Zhang Yaojun, The theoretical system of Belt and Road Initiative, Luxemburgo, Springer, 2019.

${ }^{11}$ Ivana Karaskova y Veronika Blabova, "The Logic of China's Vaccine Diplomacy", The Diplomat, 24 de marzo de 2021, https://thediplo mat. com/2021/03/the-logic-of-chinas-vaccine-diplomacy/

12 Antigua y Barbuda, Trinidad y Tobago, Barbados, Jamaica, Panamá, Costa Rica y Granada son los ocho miembros BRI que no recibieron donaciones. 


\section{MAPA 1}

Exportaciones y donaciones de China y membresía a la BRI en América Latina (al 26 de julio de 2021)

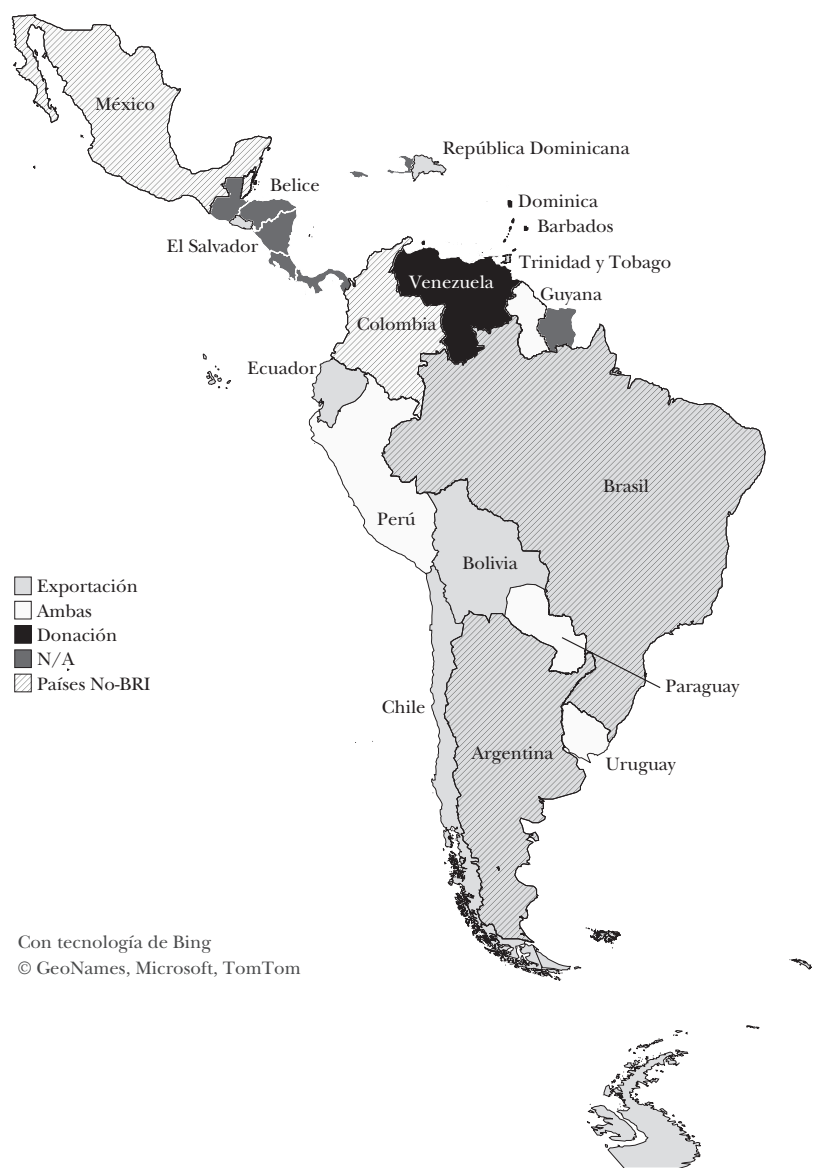

Fuente: elaboración propia con base en BRIDGe, "China Covid-19 Vaccine Tracker”, 26 de julio de 2021, https:/ / bridgebeijing.com/our-publica tions/our-publications-1/china-covid-19-vaccines-tracker/\#comment-2 (consulta del 26 de julio de 2021) y Global Health Centre, "Covid-19 Vaccine Donations", Graduate Institute of International and Development Studies, 4 de junio de 2021, https://public.tableau.com/app/profile/ global.health.center4838/viz/DonationsMaps_16227998507010/Indian SecArr (consulta del 1 de agosto de 2021). 
Si bien la consolidación de la BRI ha sido una de las guías principales de la estrategia geopolítica, esa centralidad no ha implicado desatender otros aspectos fundamentales de la política exterior como el impulso a asociaciones integrales con otros países que poseen importante peso político y económico para Beijing. En este caso, se trata de aquellos que mantienen un estatus de "asociación estratégica amplia" con China, como los casos de Argentina, Brasil y México; o bien países con los que Beijing procura establecer "relaciones diplomáticas especiales", como Colombia, aliado natural de Estados Unidos en Sudamérica. ${ }^{13}$ De esa manera, las vinculaciones tácticas que ingresan en la agenda de política exterior china son amplias, desde asegurar la continuidad de proyectos estratégicos, promover inversiones en infraestructura y transferencia tecnológica de quinta generación, hasta contribuir a la internacionalización del renminbi. La puesta en práctica de esas dimensiones de la estrategia geopolítica refleja que China no sólo ha intentado ocupar espacios relegados por Estados Unidos en la región, sino que ha añadido un mayor impulso a la competencia estratégica en sectores que Washington tradicionalmente ha dominado y en países con los que ha mantenido estrechas alianzas políticas. ${ }^{14} \mathrm{El}$ ejemplo emblemático pareciera ser Colombia que, pese a ser uno de los aliados más cercanos de Washington en la región, dio un paso histórico al apoyar a China en el Consejo de Derechos Humanos de las Naciones Unidas poco después de haber recibido vacunas de Beijing. ${ }^{15}$

13 Jamaica (desde 2005), Costa Rica (2015) y Uruguay (2016) tienen un estatus de sociedad estratégica; mientras que Argentina (2014), Brasil (2012), Chile (2016), Ecuador (2016), México (2013), Perú (2013) y Venezuela (2014) poseen un estatus de sociedad estratégica integral.

${ }^{14}$ Francisco Urdínez, Fernando Mouron, Luis Schenoni y Amâncio de Oliveira, "Chinese economic statecraft and US hegemony in Latin America: an empirical analysis, 2003-2014", Latin American Politics and Society, vol. 58, núm. 4, 2016, pp. 3-30.

15 "Colombia aplaude los avances en derechos humanos de China", El Tiempo, 24 de marzo de 2021, https://www.eltiempo.com/politica/go- 
Otros ejemplos de vinculación táctica de cuestiones con aliados estratégicos se asientan fundamentalmente en el despliegue de una diplomacia económica, cuyo epicentro corresponde a la disputa con Estados Unidos por el control de tecnologías de última generación. Los ejemplos de Brasil y República Dominicana muestran, sin lugar a dudas, el alcance de la lógica empleada y la forma en que la disputa con Washington permea las estrategias geopolíticas de Beijing. En ambos países, aunque no está todo dicho, China pareciera haber logrado imponer un cambio de rumbo en las reglas de licitación del mercado de 5G, al alterar la aproximación inicial de esos países a la iniciativa estadounidense Clean Network ${ }^{16}$ y asegurarse del ingreso de la firma Huawei en la competencia local. ${ }^{17}$ Entonces, ¿son las transacciones de vacunas una confirmación de la consecución de mayores accesos e influencia de Beijing en la región? ¿Haber llegado primero con las vacunas en la carrera con Estados Unidos es un indicador suficiente de confirmación o cabe esperar observar cómo evoluciona la tendencia en los próximos meses?

La defensa del principio de "una sola China" es otra de las bases de la estrategia geopolítica de China. En ese ámbito, el foco principal han sido los países de Centroamérica y el Caribe, un subconjunto en el que se localizan 8 de los 17 países que aún reconocen formalmente a Taiwán. Los instrumentos políticos de presión por excelencia en esos escenarios han sido las donaciones directas e indirectas. Un claro

bierno/colombia-aplaude-los-avances-en-derechos-humanos-de-china-575906

16 "Clean Network" es una iniciativa del Departamento de Estado que vincula las cuestiones de transparencia en la tecnología 5G con asuntos de seguridad nacional.

${ }^{17}$ Ezequiel Carman y Joseph Carl, "A U.s. vaccine diplomacy strategy for Latin America and the Caribbean", Global Americans, 15 de junio de 2021, https://theglobalamericans.org/2021/06/a-u-s-vaccine-diplomacystrategy-for-latin-america-and-the-caribbean/ y Marcela Vélez-Plickert, "La lucha entre EE.UU. y China por conquistar Latinoamérica con sus vacunas", DF MAS, 4 de julio de 2021, https://dfmas.df.cl/df-mas/glocal/la-lu cha-entre-ee-uu-y-china-por-conquistar-latinoamerica-con-sus-vacunas 


$$
\begin{gathered}
\text { CUADro } 2 \\
\begin{array}{c}
\text { Exportaciones de China a América Latina } \\
\text { (al } 26 \text { de julio de 2021) }
\end{array}
\end{gathered}
$$

\begin{tabular}{lccccc}
\hline \multicolumn{1}{c}{ País } & $\begin{array}{c}\text { Miembro } \\
\text { BRI }\end{array}$ & $\begin{array}{c}\text { Reconoce a } \\
\text { Taiwán }\end{array}$ & Vacuna & Dosis & $\begin{array}{c}\text { Dosis c/100 } \\
\text { habitantes }\end{array}$ \\
\hline Chile & Sí & No & Sinovac, Cansino & 17471476 & 92 \\
Uruguay & Sí & No & Sinovac & 1750000 & 51 \\
R. Dominicana & Sí & No & Sinovac, Sinopharm & 5268000 & 49 \\
Brasil & No & No & Sinovac & 29200000 & 14 \\
Ecuador & Sí & No & Sinovac, Cansino & 1500000 & 9 \\
México & No & No & Sinovac, & 9825000 & 8 \\
& & & Sinopharm, & & \\
Bolivia & Sí & No & CanSino & & 7 \\
Argentina & No & No & Sinopharm & 834000 & 7 \\
Colombia & No & No & Sinovac & 2972200 & 6 \\
Perú & Sí & No & Sinopharm & 1300000 & 4 \\
Paraguay ** & No & Sí & Sinovac, Sinopharm & 250000 & 4 \\
\hline TOTAL & & & & 73370676 & \\
\hline
\end{tabular}

Fuente: elaboración propia con base en BRIDGe, "China Covid-19 Vaccine Tracker", 26 de julio de 2021, https://bridgebeijing.com/our-publi cations/our-publications-1/china-covid-19-vaccines-tracker/\#comment-2 (consulta del 26 de julio de 2021).

ejemplo de las primeras fueron las donaciones enviadas a Guyana tras rescindir un acuerdo con Taiwán para la apertura de una oficina comercial en ese país. ${ }^{18}$ Son ilustrativas de las segundas, en tanto, las donaciones de Chile a Paraguay y de Emiratos Árabes Unidos a Belice, que de manera funcio-

${ }^{18}$ Bert Hoffmann, "El Caribe, China y la geopolítica de las vacunas", Nueva Sociedad, abril de 2021, https:/ / nuso.org/articulo/la-bendicion-delcaribe / 
nal para Beijing ayudaron a ejercer presión sobre Taiwán. En el Caribe es fundamental el apoyo logístico del banco de vacunas de la Alianza Bolivariana para los Pueblos de Nuestra América-Tratado de Comercio de los Pueblos (ALBA-TCP) a través de la aerolínea venezolana Conviasa. ${ }^{19}$

\section{CuAdro 3 \\ Donaciones de China a América Latina \\ (al 26 de julio de 2021)}

\begin{tabular}{lcccccc}
\hline \multicolumn{1}{c}{ País } & $\begin{array}{c}\text { Membresía } \\
\text { a BRI }\end{array}$ & $\begin{array}{c}\text { Reconoce a } \\
\text { Taíwán }\end{array}$ & $\begin{array}{c}\text { Triangulación/ } \\
\text { Canal }\end{array}$ & Vacuna & $\begin{array}{r}\text { Número } \\
\text { de dosis }\end{array}$ & $\begin{array}{c}\text { Dosis } \\
\text { cada 100 } \\
\text { habitantes }\end{array}$ \\
\hline Dominica & Sí & No & Bilateral & Sinopharm & 20000 & 28 \\
El Salvador & Sí & No & Bilateral & Sinovac & 1650000 & 26 \\
Barbados & Sí & No & Bilateral & Sinopharm & 30000 & 10 \\
Guyana & Sí & No & Bilateral & Sinopharm & 20000 & 3 \\
Belice & No & Sí & Árabes Unidos & Sinopharm & 10000 & 3 \\
Venezuela & Sí & No & Bilateral & Sinopharm & 500000 & 2 \\
Bolivia & Sí & No & Bilateral & Sinopharm & 200000 & 2 \\
Ecuador & Sí & No & Chile [20000] & Sinovac & 220000 & 1 \\
República & Sí & No & Bilateral & Sinovac & 50000 & 0.1 \\
Dominicana & & & & & \\
Paraguay & No & Sí & Chile & Sinovac & 20000 & 0.1 \\
\hline Total & & & & 1220000 & \\
\hline
\end{tabular}

Fuente: Global Health Centre, "Covid-19 Vaccine Donations", Graduate Institute of International and Development Studies, 4 de junio de 2021, https://public.tableau.com/app/profile/global.health.center4838/viz/ DonationsMaps_16227998507010/IndianSecArr (consulta del 1 de agosto de 2021).

19 "Antigua y Barbuda recibe 20 mil dosis de la vacuna china Sinopharm a través del puente aéreo del Banco del alba", ALBA-TCP, 2021, https://www.albatcp.org/2021/06/30/antigua-barbuda-vacuna-si nopharm/ 
La estrategia geopolítica de Beijing se presenta, además, como una extensión del proceso de transformación de su política exterior, de internacionalización del Estado y de incremento del rol internacional de las provincias. ${ }^{20}$ Esto marca el paso de una estrategia originalmente centrada en su proyección de Estado a Estado hacia una suerte de "diplomacia de base”, de corte pragmático y más caótica en su expansión, siguiendo la clasificación de Juan Tokatlian. ${ }^{21}$ A diferencia de Estados Unidos, que mantiene una estrategia vertical o de cúpula, Beijing se proyecta sobre un rango mayor de actores y de manera más descentralizada, lo que habilita la celebración de acuerdos de exportación con gobiernos subnacionales o la suscripción de contratos para la producción local con laboratorios (véase cuadro 4).

\section{Cuadro 4}

Acuerdos de China con gobiernos subnacionales y actores no estatales de América Latina (al 26 de julio de 2021)

\begin{tabular}{|c|c|c|c|c|c|}
\hline $\begin{array}{l}\text { Gobierno } \\
\text { subnacional / } \\
\text { Institución }\end{array}$ & País & $\begin{array}{c}\text { Miembro } \\
\text { BRI }\end{array}$ & Vacuna & $\begin{array}{l}\text { Tipo de } \\
\text { vínculo }\end{array}$ & Dosis \\
\hline Córdoba & Argentina & No & CanSino & $\begin{array}{l}\text { contrato de } \\
\text { exportación }\end{array}$ & 1000000 \\
\hline Santa Fe & Argentina & No & $\begin{array}{l}\text { Sinopharm } \\
\text { [G42 Emiratos } \\
\text { Árabes] }\end{array}$ & $\begin{array}{l}\text { contrato de } \\
\text { triangulación }\end{array}$ & $s / d$ \\
\hline Santa Fe & Argentina & No & CanSino & $\begin{array}{l}\text { contrato de } \\
\text { exportación }\end{array}$ & 1000000 \\
\hline Buenos Aires & Argentina & No & CanSino & $\begin{array}{l}\text { negociación con } \\
\text { gobierno nacional }\end{array}$ & $\mathrm{s} / \mathrm{d}$ \\
\hline
\end{tabular}

${ }^{20}$ Rubén González-Vicente, "The internationalization of the Chinese state”, Political Geography, vol. 30, núm. 7, 2011, pp. 402-411.

${ }^{21}$ Juan Gabriel Tokatlian, "Equidistancia y para-diplomacia", Clarín, 13 de junio de 2021, https://www.clarin.com/opinion/equidistancia-di plomacia_0_Zjly6EHYM.html 


\section{CuAdro 4 (conclusión)}

\begin{tabular}{|c|c|c|c|c|c|}
\hline Asunción & Paraguay & No & Sinovac & $\begin{array}{l}\text { donación } \\
\text { Conmebol }\end{array}$ & 50000 \\
\hline $\begin{array}{l}\text { San Pablo / } \\
\text { Instituto Butantan }\end{array}$ & Brasil & No & Sinovac & $\begin{array}{l}\text { contrato para } \\
\text { producción local }\end{array}$ & 100000000 \\
\hline Jujuy & Argentina & No & Sinopharm & $\begin{array}{l}\text { contrato de } \\
\text { exportación }\end{array}$ & 1000000 \\
\hline $\begin{array}{l}\text { Ciudad Autónoma } \\
\text { de Buenos Aires }\end{array}$ & Argentina & No & CanSino & $\begin{array}{l}\text { contrato de } \\
\text { exportación }\end{array}$ & $\mathrm{s} / \mathrm{d}$ \\
\hline Entre Ríos & Argentina & No & Cansino & $\begin{array}{c}\text { negociación con } \\
\text { Santa Fe y Córdoba }\end{array}$ & $\mathrm{s} / \mathrm{d}$ \\
\hline Mendoza & Argentina & No & Cansino & $\begin{array}{c}\text { negociación } \\
\text { conjunta con CABA }\end{array}$ & $\mathrm{s} / \mathrm{d}$ \\
\hline Drugmex & México & No & CanSino & $\begin{array}{l}\text { contrato para } \\
\text { producción local }\end{array}$ & 35000000 \\
\hline Sinergium Biotech & Argentina & No & Sinopharm & $\begin{array}{l}\text { contrato para } \\
\text { producción local }\end{array}$ & 48000000 \\
\hline
\end{tabular}

Fuente: elaboración propia con base en "Sinovac evalúa producción de vacunas en Chile y anunció desarrollo de dosis contra variante Gamma”, CNN Chile, 19 de julio de 2021, https://www.cnnchile.com/coronavirus/ sinovac-evalua-produccion-vacunas-chile-desarrollo-dosis-variante-gamma_20210719/ (consulta del 19 de julio de 2021); “Qué provincias buscan comprar vacunas por su cuenta y con quién negocian”, Cronista, 30 de mayo de 2021, https://www.cronista.com/economia-politica/mas-provin cias-negocian-la-compra-de-dosis-para-acelerar-la-vacunacion/ (consulta del 30 de mayo de 2021); "Polémica en puerta: llegan a Uruguay las vacunas donadas a la Conmebol”, La Voz, 28 de abril de 2021, https://www.lavoz. com.ar/deportes/futbol/polemica-en-puerta-llegan-a-uruguay-las-vacu nas-donadas-a-la-conmebol/ (consulta del 30 de mayo de 2021); "Jujuy inició gestiones con China para comprar 1 millón de vacunas contra el coronavirus", Infobae, 20 de mayo de 2021, https:/ / www.infobae.com/po litica/2021/05/20/jujuy-inicio-gestiones-con-china-para-comprar-1-millon-de-vacunas-contra-el-coronavirus/ (consulta del 14 de junio de 2021); "El gobierno de Kicillof firmó un acuerdo para comprar 10 millones de dosis de vacunas Covaxin de un laboratorio de la India”, Infobae, 4 de junio de 2021, https:/ /www.infobae.com/politica/2021/06/04/el-gobierno-dekicillof-firmo-un-acuerdo-para-comprar-10-millones-de-dosis-de-vacunascovaxin-de-un-laboratorio-de-la-india/ (consulta del 14 de junio de 2021); 
Rusia y el desafio a Estados Unidos

La estrategia geopolítica de Rusia en la región fue, al igual que China, temprana y persiguió claros lineamientos políticos y económicos. Los primeros corresponden a un intento por plantear un desafío político a Estados Unidos en su propia periferia como espejo del involucramiento de Washington en la periferia de Moscú, principalmente a través de la ayuda militar y el apoyo a Ucrania. ${ }^{22}$ Los segundos se verifican en la articulación de estrategias con los laboratorios farmacéuticos rusos y otros de la región, como parte de la búsqueda de nuevos mercados en reacción a las sanciones económicas impuestas por Estados Unidos y la Unión Europea desde 2014, que la impulsan a desarrollar vinculaciones más allá de su esfera de influencia tradicional de Eurasia en los rubros de la biotecnología, industria, energía, tecnología y defensa. Aquí, de manera similar a Beijing, los instrumentos de diplomacia económica a disposición de Rusia han sido la exportación y la internacionalización de la producción de vacunas. ${ }^{23}$

"Santa Fe firmó un acuerdo para comprar un millón de vacunas CanSino", Infobae, 11 de junio de 2021, https: / / www.infobae.com/politica/2021/06/ 12/santa-fe-firmo-un-acuerdo-para-comprar-un-millon-de-vacunas-cansi no/ (consulta del 14 de junio de 2021), y “Córdoba firmó un acuerdo para comprar un millón de vacunas del laboratorio CanSino”, Infobae, 14 de junio de 2021, https:/ / www.infobae.com/politica/2021/06/15/cordobafirmo-un-acuerdo-para-comprar-un-millon-de-vacunas-del-laboratorio-can sino/ (consulta del 14 de junio de 2021).

${ }^{22}$ En plena pandemia, el gobierno de Biden donó 60 millones de dólares en ayuda militar a su homólogo ucraniano, sumándose a los más de 2 millones donados desde 2014. "Ucrania recibe muestra de apoyo de EEUU. frente a agresión rusa”, $D W, 1$ de septiembre de 2021, https:/ / www. dw.com/es/ucrania-recibe-muestra-de-apoyo-de-eeuu-frente-a-agresiónrusa/a-59056703 (consulta del 15 de septiembre de 2021).

${ }^{23}$ Las dosis donadas por Rusia fueron sólo en concepto de muestras gratuitas a Nicaragua y Belice (6000 y 20000 dosis, respectivamente), países que ya estaban considerando la adquisición de esas vacunas. Yurany Arciniegas, "Nicaragua recibe una donación de la dosis Sputnik V para comenzar a vacunar contra el covid-19”, France 24, 24 de febrero de 2021, https:/ / www.france24.com/es/\%C3\%A1frica/20210224-covid19hoy-no 


\section{MAPA 2}

Compromisos de exportaciones en dosis cada 100 habitantes y acuerdos de descentralización de la producción de Rusia en América Latina (al 24 de junio de 2021)

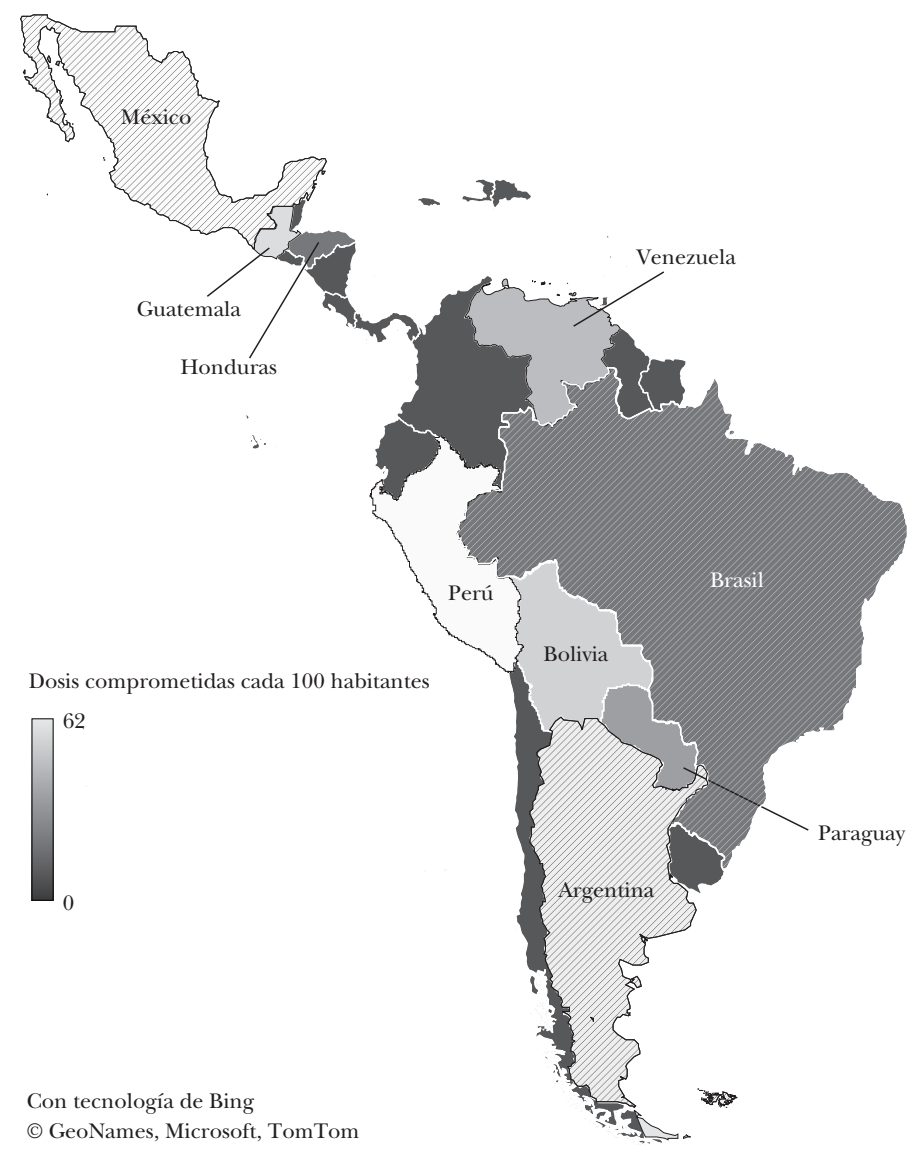

Fuente: elaboración propia con base en "Sputnik V covid-19 vaccine", Statista Research Department, 24 de junio de 2021, https://www.statista. com/topics/7762/sputnik-v-covid-19- vaccine/ (consulta del 25 de junio de 2021).

Referencia: la textura a rayas corresponde a países con contratos con firmas rusas para producción local. 
Si bien Rusia fue el primer país en anunciar la aprobación de una vacuna, el avance de las vacunas rusas ha abierto todo tipo de polémicas en el contexto de una fuerte campaña de desprestigio desde Washington sobre la eficacia y la seguridad de la Sputnik V. Países como Argentina, Brasil, Bolivia, Venezuela, Paraguay y Perú se aproximaron rápidamente a Moscú para intentar recibir dosis. A partir de allí, se abrieron especulaciones sobre cómo las vacunas servirían como conducto para el mejoramiento transitorio de relaciones bilaterales o para facilitar el camino diplomático y ampliar la cooperación industrial, tecnológica y política. Un ejemplo de ello ocurrió con Bolivia, donde la llegada de las primeras 20000 dosis importadas de vacuas rusas habilitó una discusión sobre la posible reactivación de proyectos como la construcción de una central nuclear y la explotación de reservas de gas natural y de litio. ${ }^{24}$ Otro caso ilustrativo fue el de México, donde abrió un canal de diálogo para poner en agenda la primera visita de un presidente ruso a ese país en casi una década. En cualquier caso, la Sputnik V habilitó varios canales de intercambio con Rusia que fueron debilitándose a medida que los países comenzaron a experimentar serios retrasos en las entregas. ${ }^{25}$

ticias-pandemia-vacunacion-covax-francia-bolivia; Samantha Kiernan, Serena Tohme, Kailey Shanks y Basia Rosenbaum, "The Politics of Vaccine Donation and Diplomacy Is a friend in need a friend indeed?", Think Global Health, 4 de junio de 2021, https://www.thinkglobalhealth.org/article/ politics-vaccine-donation-and-diplomacy

${ }^{24}$ Aislinn Laing y Cassandra Garrison, "Amid scramble for covid-19 vaccine, Latin America turns to Russia”, Reuters, 1 de mayo de 2021, https:/ / www.reuters.com/business/healthcare-pharmaceuticals/amid-scramblecovid-19-vaccine-latin-america-turns-russia-2021-03-01/

${ }^{25}$ Rusia ha podido cumplir con menos del $30 \%$ de los contratos asumidos, salvo el caso de Argentina, donde ha entregado el $40 \%$ de las vacunas comprometidas y en Paraguay, con el 29\%. A raíz de estos incumplimientos, Guatemala canceló su contrato con el Instituto Gamaleya de 8 millones de dosis y el Ministerio de Salud de Brasil ha considerado cancelar el propio de 10 millones. Chase Harrison, "In Vaccine Race, Russia Trips in Latin America”, As/COA, 12 de agosto de 2021, https:/ /www.as-coa.org/articles/ vaccine-manufacturing-race-russia-trips 


\section{CuAdro 5}

Compromisos de exportaciones en dosis ordenadas versus entregadas y producción local de vacunas rusas en América Latina (al 24 de junio de 2021)

\begin{tabular}{lcccc}
\hline \multicolumn{1}{c}{ Países } & $\begin{array}{c}\text { Dosis } \\
\text { comprometidas }\end{array}$ & $\begin{array}{c}\text { Porcentaje de dosis } \\
\text { entregadas }\end{array}$ & $\begin{array}{c}\text { Dosis comprometidas } \\
\text { cada }\end{array}$ 100 habitantes & $\begin{array}{c}\text { Capacidad de } \\
\text { producción local }\end{array}$ \\
\hline Perú & 20000000 & $0 \%$ & 62 & $\mathrm{n} / \mathrm{a}$ \\
Argentina & 22000000 & $40 \%$ & 49 & 12000000 \\
Guatemala & 8000000 & $12 \%$ & 48 & $\mathrm{n} / \mathrm{a}$ \\
Bolivia & 5200000 & $14 \%$ & 45 & $\mathrm{n} / \mathrm{a}$ \\
Venezuela & 10000000 & $14 \%$ & 35 & $\mathrm{n} / \mathrm{a}$ \\
México & 24000000 & $17 \%$ & 19 & $\mathrm{~s} / \mathrm{d}$ \\
Paraguay & 1000000 & $29 \%$ & 14 & $\mathrm{n} / \mathrm{a}$ \\
Brasil & 10000000 & $\mathrm{~s} / \mathrm{d}$ & 5 & 8000000 \\
Honduras & 70000 & $1 \%$ & 1 & $\mathrm{n} / \mathrm{a}$ \\
\hline Total & 100270000 & & & \\
\hline
\end{tabular}

Fuente: elaboración propia con base en "Sputnik V covID-19 vaccine", Statista Research Department, 24 de junio de 2021, https://www.statista. com/topics/7762/sputnik-v-covid-19-vaccine/ (consulta del 13 de septiembre de 2021) y Chase Harrison, "In Vaccine Race, Russia Trips in Latin America”, As/COA, 12 de agosto de 2021, https://www.as-coa.org/articles/vacci ne-manufacturing-race-russia-trips

\section{Estados Unidos y los aliados europeos frente a China y Rusia}

El avance de las vacunas chinas y rusas en la región se aprovechó del "nacionalismo de vacunas" que primó en Estados Unidos durante el primer semestre de 2021. Tanto la administración de Trump como la de Biden invocaron la Defense Production Act con el propósito de combatir el covid-19 y de aliviar los cuellos de botella en los suministros de insumos necesarios para la producción de vacunas. Pese a que las firmas farmacéuticas nacionales habían sido capaces de atender la demanda de la población nacional e incluso presentar excedentes de vacunas, el primer antecedente de donación de vacunas se registró recién en mayo de 2021, cuando el gobierno de Joe Biden anunció el envío de 4.2 millones de dosis 
a Canadá y México, seguido por los compromisos de donaciones a nivel mundial del 3 y del 10 de junio, que asignaron 20 millones de dosis para América Latina. ${ }^{26}$

Dos lineamientos principales guiaron la estrategia geopolítica de donaciones de vacunas de Estados Unidos en América Latina: el primero, acompañar a una mayor presencia de agencias estatales políticas y militares de Washington en la región; el segundo, reaccionar frente al avance de las vacunas de China y Rusia en su propia periferia. De un lado, la intención, como prioridad de seguridad nacional, ha sido colocar un escudo sanitario para evitar que en la frontera entre México y Estados Unidos ingresen migrantes y "flujos ilícitos". El cálculo principal ha sido que con las poblaciones de México y de los países del Triángulo Norte (Guatemala, Honduras y El Salvador) inmunizadas, Estados Unidos se aseguraría mayor protección. ${ }^{27}$ Del otro, el despliegue de la agenda de Washington se ha basado en un diagnóstico y una reacción a la influencia "negativa" de la geopolítica de vacunas de China y Rusia en la región. Aquí los instrumentos han sido la denegación de acceso al mercado norteamericano y una fuerte campaña de desprestigio sobre las vacunas chinas y rusas.

Una de las consecuencias directas de la pandemia ha sido la expansión del rango de acción militar de Washington en la región, más allá de la experiencia en gestión de desastres. Cabe señalar que el rol del Comando Sur ha sido de vital importancia en la estrategia geopolítica, tanto en la elaboración del diagnóstico como en la afinación de la respuesta. Lo primero se reflejó en las advertencias contra el uso "maligno" de China de su influencia en materia de vacunas para impulsar la integración de la firma Huawei al mercado de $5 \mathrm{G}$ de la región. ${ }^{28}$

${ }^{26}$ Chase Harrison, "Tracker: U.S. Vaccine Donations to Latin America”, As /coA Online, 28 de julio de 2021, https:/ / www.as-coa.org/articles/ tracker-us-vaccine-donations-latin-america

${ }^{27}$ Daniel Ruvalcaba, "La política exterior de Joseph Biden hacia América Latina: un análisis prospectivo al inicio del nuevo gobierno", Revista Izquierdas, 2021, p. 14.

${ }^{28}$ Ezequiel Carman y Joseph Carl, art. cit. 
Lo segundo, en el aprovechamiento de la respuesta humanitaria a la covid-19 como pretexto para reforzar la presencia militar en el Triángulo Norte y atender las así denominadas amenazas del "narcoterrorismo", al tiempo que se colaboró con el programa de Asistencia a la Migración y a los Refugiados, y se apoyó logísticamente a los laboratorios farmacéuticos en el traslado de congeladores especiales y de otros insumos relacionados con las vacunas..$^{29}$

La exacerbación de la rivalidad con China se expresó de manera particular en los anuncios de donaciones a la región, que buscaron revertir la inicial ausencia de Washington en las primeras etapas de la pandemia y avanzar con la ayuda a aquellos países que todavía no habían recibido donaciones de China. El dato que surge de las asignaciones de donaciones es elocuente, ya que 14 de un total de 16 países de la región a los que donó Washington no habían sido congraciados por Beijing. Las excepciones fueron países que reconocen a Taiwán -como Belice, El Salvador y Paraguay- a los que las vacunas chinas llegaron de manera indirecta desde terceros países. El cuadro 6 muestra diferencias y coincidencias de destinatarios entre las donaciones estadounidenses y chinas; De éstas, Bolivia, Dominica y República Dominicana son los únicos países que recibieron donaciones de ambas potencias. La lectura de Washington parece ser que las donaciones pueden cumplir un doble papel: mostrar una mirada asistencial y compasiva frente a una región muy castigada, por un lado, y lograr con poco desembolso de recursos extender una visión de que la ayuda es más benigna que el comercio, por el otro.

${ }^{29}$ Carlos Hernández, "El Comando Sur de EE.uU. incrementará su presencia militar en America Latina", Revista de Defensa y Seguridad en España y Latinoamérica, 15 de marzo de 2020, https://www.infodefensa. com/latam/2020/03/15/noticia-comando-incrementara-presencia-militar-hemisferio.html 


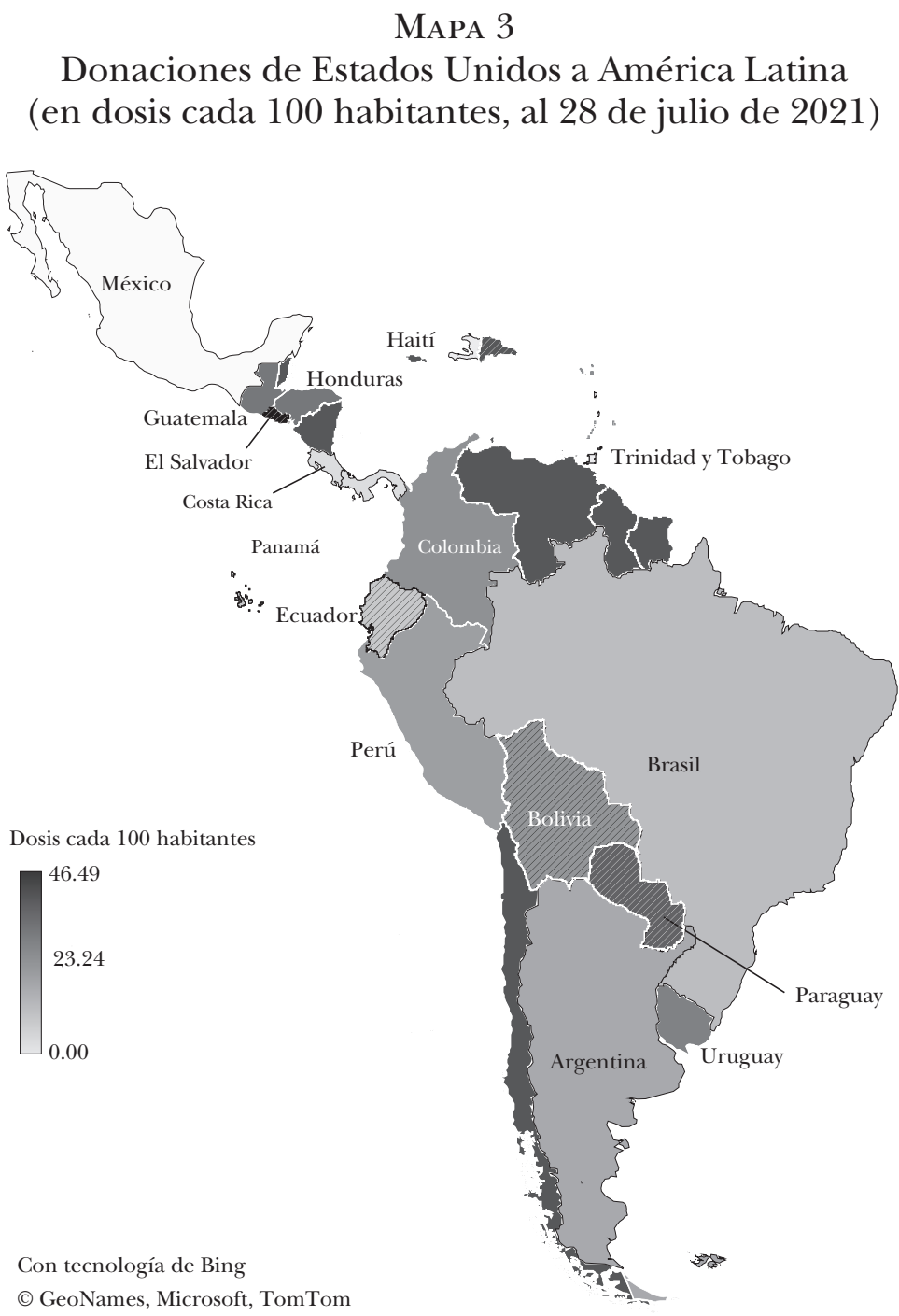

Fuente: elaboración propia con base en Chase Harrison, "Tracker: U.S. Vaccine Donations to Latin America", As/coA Online, 28 de julio de 2021, https://www.as-coa.org/articles/tracker-us-vaccine-donations-latinamerica (consulta del 28 de julio de 2021).

Referencia: la textura a rayas corresponde a los países con donaciones de vacunas chinas. 


\section{CuAdro 6}

\section{Donaciones de Estados Unidos a América Latina (hasta 28 de julio de 2021)}

\begin{tabular}{|c|c|c|c|c|c|c|}
\hline País receptor & $\begin{array}{c}\text { Base o acuerdo } \\
\text { militar }\end{array}$ & $\begin{array}{l}\text { Reconoce } \\
\text { a Taiwán }\end{array}$ & $\begin{array}{c}\text { Donaciones } \\
\text { de China }\end{array}$ & $\begin{array}{c}\text { Dosis } \\
\text { donadas } \\
\text { (en millones) }\end{array}$ & Vacuna & $\begin{array}{c}\text { Dosis } \\
c / 100 \\
\text { habitantes }\end{array}$ \\
\hline El Salvador & $\begin{array}{c}\text { Base operativa } \\
\text { (Comalapa) }\end{array}$ & No & Sí & 3.0 & Moderna & 46 \\
\hline Honduras & $\begin{array}{c}\text { Base operativa } \\
\text { (Soto Cano) }\end{array}$ & Sí & No & 3.0 & Pfizer & 30 \\
\hline Paraguay & $\begin{array}{c}\text { Acuerdo de } \\
\text { acceso (Mariscal } \\
\text { Estigarribia) }\end{array}$ & Sí & No & 2.0 & Pfizer & 28 \\
\hline Guatemala & & Sí & No & 4.5 & Moderna & 27 \\
\hline Uruguay & & No & No & 0.5 & Pfizer & 14 \\
\hline Ecuador & $\begin{array}{c}\text { Oficina de } \\
\text { Cooperación de } \\
\text { Seguridad }\end{array}$ & No & No & 2.0 & Pfizer & 12 \\
\hline Colombia & $\begin{array}{c}\text { Base } \\
\text { expedicionaria } \\
\text { e instalaciones }\end{array}$ & No & No & 6.0 & $J \& J$ & 12 \\
\hline Panamá & & No & No & 0.5 & Pfizer & 12 \\
\hline Costa Rica & & No & No & 0.5 & Pfizer & 10 \\
\hline Bolivia & & No & Sí & 1.0 & $J \& J$ & 9 \\
\hline Argentina & & No & No & 3.5 & Moderna & 8 \\
\hline Perú & $\begin{array}{c}\text { Instalación o } \\
\text { efectivos }\end{array}$ & No & No & 2.0 & Pfizer & 6 \\
\hline Haití & & Sí & No & 0.5 & Moderna & 4 \\
\hline $\begin{array}{l}\text { Trinidad y } \\
\text { Tobago }\end{array}$ & & No & No & 0 & Pfizer & 3.4 \\
\hline México & & No & No & 4.1 & $\begin{array}{c}\mathrm{J} \& \mathrm{~J} / \text { Astra } \\
\text { Zeneca }\end{array}$ & 3 \\
\hline Brasil & & No & No & 3.0 & $\mathrm{~J} \& J$ & 1 \\
\hline \multicolumn{2}{|l|}{ Total } & & & 36.1 & & \\
\hline
\end{tabular}

Fuente: elaboración propia con base en Chase Harrison, "Tracker: U.S. Vaccine Donations to Latin America", As/COA Online, 28 de julio de 2021, https:/ /www.as-coa.org/articles/tracker-us-vaccine-donations-latinamerica (consulta del 28 de julio de 2021). 
La competencia entre Washington y Beijing muestra, además de diferentes enfoques, diversas modalidades. Mientras la segunda centró su estrategia en las exportaciones y en la internacionalización gradual de su producción, la primera realizó donaciones bilaterales que combinó, a partir del anuncio de retorno a la Organización Mundial de la Salud, con contribuciones al mecanismo multilateral covax. ${ }^{30} \mathrm{La}$ evidencia demuestra que para Washington la apuesta al multilateralismo no sólo ratificó una línea discursiva de Biden en campaña, sino que fortaleció los lazos políticos y económicos con los aliados europeos de cara a la disputa con China. Fue fundamental en este ámbito el aporte de la empresa de la Universidad de Oxford/AstraZeneca que, a finales de 2020, era el único fabricante de vacunas que tenía un acuerdo con la iniciativa global covax, y realizó un esfuerzo para descentralizar su producción. Por otra parte, la vinculación con los países europeos también fue reactivada a través de empresas de biotecnología estadounidense. Moderna y Johnson \& Johnson articularon sus cadenas de producción con firmas de Francia, Alemania y España, mientras que la alemana estadounidense Pfizer/BioNTech lo hizo con firmas de Francia, Alemania y Suiza. Como lo refleja un informe de Global Health Centre, un tercio (36/122) del total de acuerdos registrados por los laboratorios farmacéu-

${ }^{30}$ En particular, este último eje fue impulsado en la reunión del G7 celebrada el 10 de junio de 2021 mediante una iniciativa de compra conjunta con aliados europeos -Reino Unido y la Unión Europea- de 500 millones de dosis de vacunas para el mecanismo de Compromiso Anticipado de Mercado (amc, por sus siglas en inglés) de covax. Gobierno de Estados Unidos, Departamento de Estado, "Secretary Anthony Blinken with Roula Khalaf of the Financial Times", Dos, 3 de mayo de 2021, https://www.state.gov/secretary-antony-j-blinken-with-roula-kha laf-of-the-financial-times/ y James Fulker, "92 low- and middle-income economies eligible to get access to Covid-19 vaccines through Gavi covax AMC", GAVI, 31 de julio de 2020, https:/ / www.gavi.org/news/media-room/ 92-low-middle-income-economies-eligible-access-covid-19-vaccines-gavicovax-amc 
ticos de Estados Unidos fueron sellados con fabricantes con sede en Europa. ${ }^{31}$

\section{La India, retador de China}

Durante el tiempo en que primó el nacionalismo de vacunas en Washington, la India adoptó una política activa de donaciones $^{32}$ en América Latina, fruto de la trayectoria y las capacidades adquiridas en el campo farmacéutico. ${ }^{33} \mathrm{Si}$ bien las exportaciones y las donaciones a la región apenas representaron 10.5 y $10.8 \%$ del total, respectivamente, la cobertura de vacunas se extendió a 20 países latinoamericanos. La explicación detrás de esta lógica es el impulso de la diplomacia económica, cuyo objetivo consistió en apalancar la exportación de vacunas y contribuir al acceso de laboratorios indios al mercado farmacéutico; no obstante, algunos analistas señalan también el interés indio de avanzar a paso firme frente

31 Global Health Centre, "covid-19 Vaccine Manufacturing Agreements”, 3 de junio de 2021, Graduate Institute of International and Development Studies, https://www.knowledgeportalia.org/covid19-vaccine-ma nufacturing (consulta del 4 de junio de 2021).

32 La iniciativa Vaccine Maitri (“Amistad de Vacunas") -lanzada en enero de 2021- lleva donadas 107 millones de dosis, exportadas de forma bilateral 357 millones y distribuidas a través de covax otras 198000 millones, alcanzando a cubrir a 93 países, en particular los países miembros de la Asociación para la Cooperación Regional del Sur de Asia (sAARC) con excepción de Pakistán y de la región de África Subsahariana. En conjunto, los países de SAARC recibieron $58 \%$ de las dosis donadas por la India. Los países miembro de sAARc son Afganistán, Bután, Maldivas, Nepal, Sri Lanka y Bangladesh. Este último se destaca con 70 millones de dosis compradas y 33 millones de dosis recibidas como donación.

${ }^{33}$ India puso en marcha tres proyectos de vacunas: Covaxin, desarrollada por Bharat Biotech en asociación con el Consejo Indio para la Investigación Médica; en segundo lugar, ZyCOV-D, desarrollada por Zydus Cadila, que espera producir más de 100 millones de dosis, y, por último, la Covishield, un proyecto del Serum Institute of India en colaboración con AstraZeneca para desarrollar una investigación original de la Universidad de Oxford. 
a China en un contexto de aumento de tensiones geopolíticas en la frontera norte. ${ }^{34}$

\section{Cuadro 7}

Donaciones de vacunas de la India a América Latina (al 20 de julio de 2021)

\begin{tabular}{lcccccc}
\hline País & Dosis & $\begin{array}{c}\text { Diáspora } \\
\text { india }\end{array}$ & $\begin{array}{c}\text { Miembro } \\
\text { Common } \\
\text { wealth }\end{array}$ & $\begin{array}{c}\text { Reconoce } \\
\text { a China }\end{array}$ & $\begin{array}{c}\text { Donaciones } \\
\text { de China }\end{array}$ & $\begin{array}{c}\text { Dosis } \\
\text { cada 100 } \\
\text { habitantes }\end{array}$ \\
\hline Dominica & 70000 & - & Sí & Sí & 50000 & 97.4 \\
Antigua y Barbuda & 40000 & - & Sí & Sí & No & 41.2 \\
San Cristóbal y & 20000 & - & Sí & No & No & 37.9 \\
$\quad$ Nieves & & & & & & \\
San Vicente y & 40000 & - & Sí & No & No & 36.2 \\
$\quad$ Granadinas & 100000 & - & Sí & Sí & No & 34.8 \\
Barbados & 25000 & - & Sí & No & No & 13.7 \\
Santa Lucía & 80000 & Sí & Sí & Sí & 20000 & 10.2 \\
Guyana & 50000 & Sí & - & Sí & No & 8.6 \\
Suriname & 25000 & Sí & Sí & No & No & 6.4 \\
Belice & 20000 & - & Sí & Sí & No & 5.1 \\
Bahamas & 200000 & - & - & No & No & 3.1 \\
Nicaragua & 40000 & Sí & Sí & Sí & No & 2.9 \\
Trinidad y Tobago & 200000 & - & - & No & No & 2.8 \\
Paraguay & 500000 & Sí & Sí & Sí & No & 1.7 \\
Jamaica & 200000 & - & - & No & No & 1.2 \\
Guatemala & 30000 & - & - & Sí & 50000 & 0.2 \\
República & & & & & & \\
Dominicana & 1640000 & & & & & \\
\hline Total & & & & & & \\
\hline
\end{tabular}

Fuente: elaboración propia con base en información del Gobierno de la India, Ministerio de Asunto Exteriores, "Vaccine Supply", 29 de mayo de 2021, https:/ / www.mea.gov.in/vaccine-supply.htm (consulta del 3 de agosto de 2021).

34 Swaminathan Natarajan, "China vs India: las claves para entender la larga disputa fronteriza que generó un enfrentamiento que dejó varios soldados muertos", BBC World Services, 5 de junio de 2020, https: / www. bbc.com/mundo/noticias-internacional-52871613 
La visión de la India sobre China, funcional a Washington, pone de relieve una serie de cuestiones conexas vinculadas a la creciente influencia china en la región. Por ejemplo, ¿no comparten Nueva Delhi y Beijing la competencia por el acceso a mercados exportadores de alimentos? ¿No debería la India aprovecharse de los vacíos que deja la política exterior de China para avanzar en la región? ¿No comparten acaso Estados Unidos y la India la preocupación por la creciente influencia china en sus respectivas periferias? Algunos informes indican que la rivalidad sino-india se manifestó de manera particular en la pandemia. La preferencia india a desembarcar con vacunas en países que reconocen a Taiwán o bien aprovechar la ausencia de las donaciones de Beijing en determinados países expresa una tendencia. ${ }^{35}$ Los datos de transacciones muestran que India donó a ocho países aliados de Taiwán (Antigua y Barbuda, San Cristóbal y Nieves, San Vicente y Granadinas, Santa Lucía, Belice, Nicaragua, Paraguay y Guatemala); cubrió las demandas de 12 países de la región que no recibieron donaciones chinas y envió vacunas a Brasil a raíz de una crisis de confianza sobre las vacunas de China. La racionalidad parece ser suficientemente clara.

${ }^{35}$ Sashi Tharoor, "India's Smart Vaccine Diplomacy", Project Syndicate, 11 de marzo de 2021, https://www.project-syndicate.org/commentary/ india-covid19-vaccine-diplomacy-by-shashi-tharoor-2021-03 


\section{MAPA 4}

Exportaciones y donaciones de vacunas de la India en América Latina (al 29 de mayo de 2021)

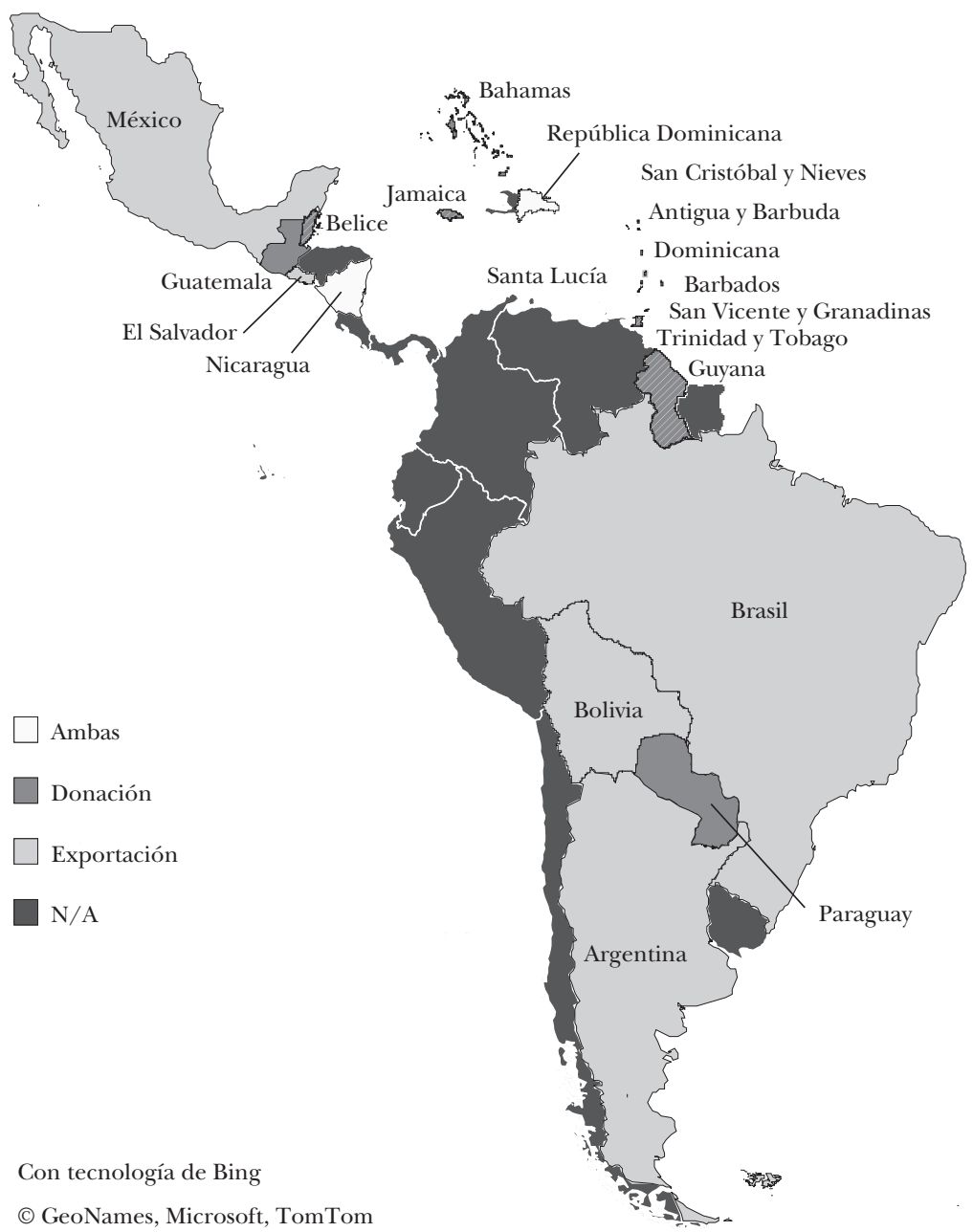

Fuente: Gobierno de la India, Ministerio de Asuntos Exteriores, "Vaccine Supply", 29 de mayo de 2021, https://www.mea.gov.in/vaccine-supply.htm (consulta del 3 de agosto de 2021).

Referencia: la textura a rayas indica los países en donde existe diáspora o población de ascendencia india. 


\section{Conclusiones}

Las estrategias geopolíticas detrás de las transacciones de vacunas de China y Estados Unidos arrojan un claro denominador común: la puja por accesos e influencia política y económica se muestra en ascenso. La exacerbación de esta lógica en la respuesta farmacéutica a la pandemia coloca a la región latinoamericana frente a una mayor exposición en el marco de una rivalidad creciente entre las superpotencias. A su vez, otras potencias productoras, como el Reino Unido, los países europeos y la India tienen un papel funcional a Estados Unidos, participando así en la competencia frente a las vacunas de China y Rusia y alimentando una fuerte campaña de desprestigio en torno de los intereses "malignos" sino-rusos en la región, mientras en paralelo se busca obtener acceso a mercados e incrementar la influencia política.

En esa puja, China dio los primeros golpes, aunque no los definitivos. Se verifica una coherencia estratégica: el ejercicio de una diplomacia económica para proyectar la BRI y otras alianzas estratégicas, en la faz ofensiva, y el apoyo a la política de "una sola China", en la faz defensiva. Lo primero se manifiesta de manera clara con Chile y Uruguay, socios de la BRI, y países como Brasil, México y Argentina, aliados para la producción local. Lo segundo se ejerce a través de las donaciones tanto en el Caribe como en el Cono Sur, siendo los principales focos El Salvador y, de manera indirecta, Paraguay. La estrategia de Beijing podría resumirse así: en lo ofensivo, apoyo a empresas y acceso a mercados; en lo defensivo, cerco a Taiwán y protecciones frente a Estados Unidos. Rusia, en tanto, demuestra coincidencias con China, y un interés en desafiar a Estados Unidos, además de buscar contrarrestar las sanciones económicas occidentales.

Del otro bando, Estados Unidos se enfocó en primera instancia en garantizar las vacunas para su población, pero a medida que la difusión tecnológica vinculada a la producción de vacunas chinas y rusas fueron erosionando esa posición, el gobierno de Biden implementó una estrategia geopolítica 
centrada en la rivalidad con el gigante asiático, el desprestigio a Rusia y la atención a cuestiones de seguridad nacional (migraciones y fronteras), además de impulsar el retorno a los mecanismos multilaterales. En una primera fase, India actuó como potencia productora satélite y subsidiaria de su aliado norteamericano, impulsó una diplomacia económica acotada, destinada a ganar mercados en Argentina, Brasil y México, y se embarcó a ocupar vacíos de China en el Caribe a través de donaciones.

\section{Cuadro 8}

Dimensiones estratégicas de la geopolítica de vacunas en América Latina

\begin{tabular}{|c|c|c|c|c|}
\hline $\begin{array}{c}\text { Países / nivel } \\
\text { de análisis }\end{array}$ & $\begin{array}{c}\text { Estados Unidos } \\
\text { y aliados europeos }\end{array}$ & China & India & Rusia \\
\hline $\begin{array}{c}\text { Preferencias } \\
\text { políticas } \\
\text { ofensivas }\end{array}$ & $\begin{array}{c}\text { Puja de accesos } \\
\text { con China / } \\
\text { Retorno al } \\
\text { multilateralismo }\end{array}$ & $\begin{array}{l}\text { Robustecer la } \\
\text { BRI / Puja de } \\
\text { accesos con } \\
\text { Estados Unidos }\end{array}$ & $\begin{array}{c}\text { Cubrir vacíos de } \\
\text { China }\end{array}$ & $\begin{array}{c}\text { Desafío a Estados } \\
\text { Unidos en su } \\
\text { periferia }\end{array}$ \\
\hline $\begin{array}{c}\text { Preferencias } \\
\text { políticas } \\
\text { defensivas }\end{array}$ & $\begin{array}{c}\text { Seguridad } \\
\text { nacional, } \\
\text { fronteras y } \\
\text { migraciones }\end{array}$ & $\begin{array}{c}\text { Política de } \\
\text { una sola China } \\
\text { (acorralamiento } \\
\text { a Taiwán) }\end{array}$ & $\begin{array}{c}\text { Reacción al } \\
\text { avance de China } \\
\text { en el Sur de Asia }\end{array}$ & $\begin{array}{c}\text { Reacción a } \\
\text { sanciones } \\
\text { económicas y } \\
\text { búsqueda de } \\
\text { nuevos mercados }\end{array}$ \\
\hline $\begin{array}{l}\text { Diplomacia } \\
\text { económica }\end{array}$ & De cúpula & De base & De cúpula & De base \\
\hline $\begin{array}{l}\text { Presencia en } \\
\text { exportaciones } \\
\text { a la región }\end{array}$ & - & 11 países & 7 países & 8 países \\
\hline $\begin{array}{c}\text { Presencia en } \\
\text { donaciones a la } \\
\text { región }\end{array}$ & $\begin{array}{l}16 \text { países } \\
\text { (aportes a } \\
\text { Covax) }\end{array}$ & 10 países & $\begin{array}{l}16 \text { países } \\
\text { (aportes a } \\
\text { covax) }\end{array}$ & 2 países \\
\hline $\begin{array}{l}\text { Desconcentración } \\
\text { de la producción }\end{array}$ & $\begin{array}{l}3 \text { países (Astra } \\
\text { Zeneca - Reino } \\
\text { Unido/Suecia) }\end{array}$ & 5 países & - & 5 países \\
\hline $\begin{array}{c}\text { Vinculaciones } \\
\text { tácticas }\end{array}$ & Sí & Sí & Sí & Sí \\
\hline
\end{tabular}


CuAdro 8 (conclusión)

\begin{tabular}{|c|c|c|c|c|}
\hline $\begin{array}{c}\text { Vinculaciones } \\
\text { sustantivas }\end{array}$ & No & Sí & No & Sí \\
\hline $\begin{array}{c}\text { Principales } \\
\text { firmas }\end{array}$ & $\begin{array}{c}\text { Pfizer/ } \\
\text { BioNtech, } \\
\text { Moderna, } \\
\text { Johnson \& } \\
\text { Johnson ystra } \\
\text { Zeneca/Oxford }\end{array}$ & $\begin{array}{c}\text { Sinopharm } \\
\text { (firma pública), } \\
\text { Sinovac (firma } \\
\text { privada) y } \\
\text { CanSino }\end{array}$ & $\begin{array}{c}\text { Bharat Biotech, } \\
\text { Serum Institute } \\
\text { of India }\end{array}$ & $\begin{array}{c}\text { Gamaleya y } \\
\text { Vector Institute }\end{array}$ \\
\hline
\end{tabular}

Fuente: elaboración propia.

En suma, los hallazgos de este trabajo basados en la evidencia empírica pueden colaborar en la comprensión de las interacciones entre estructura de poder global, preferencias políticas y estrategias que dan forma a la actual geopolítica de vacunas. Se han encontrado dos tipos de influencia: en China y Rusia prevalecen preferencias políticas ofensivas y defensivas combinadas con diplomacia económica de base; en Estados Unidos, Europa e India las preferencias políticas son ofensivas y defensivas, y la diplomacia económica es de cúpula. En cuanto a los instrumentos, mientras que en la primeras predominan las exportaciones y la desconcentración de la producción, en las segundas priman las donaciones y las contribuciones al mecanismo covax. A su turno, las estrategias de las primeras, basadas en el comercio y las inversiones, vinculan cuestiones tácticas y sustantivas; en cambio, las segundas están centradas en la ayuda humanitaria y vinculan sólo cuestiones tácticas.

Así, los ejemplos explorados muestran dos grupos opuestos en su aproximación a la geopolítica de vacunas. Esa divergencia debería considerarse también en cuanto a su relevancia para el acceso a los biológicos, dado que estas potencias productoras son las principales proveedoras de la región.

La posición vulnerable, periférica y dependiente de América Latina en la distribución global de capacidades tecnológicas de producción de vacunas torna imperativos la 
producción de conocimiento y el debate académico sobre la problemática. Por cierto, este trabajo deja interrogantes para futuras investigaciones, principalmente relacionados con la necesidad de recolectar datos cualitativos y cuantitativos sobre la geopolítica de vacunas de países latinoamericanos, para analizar con más detalle cómo se reproduce en América Latina la competencia geopolítica desde países medianos y de qué manera Estados productores, como Argentina, México, Brasil, Venezuela y Cuba, se insertan en la dinámica global y regional. Además, futuros trabajos podrían indagar acerca de la naturaleza de los problemas planteados en este artículo desde una perspectiva comparada con otras regiones en desarrollo, como África o Asia, para comprender en profundidad las dimensiones, los procesos y las estrategias geopolíticas de potencias productoras de vacunas. ¿Qué pone hoy en movimiento las cadenas de suministro de vacunas? La desigualdad en la superficie, la geopolítica en el núcleo.

\section{Bibliografía}

ALBA-TCP, "Antigua y Barbuda recibe 20 mil dosis de la vacuna china Sinopharm a través del puente aéreo del Banco del ALBA", 2021, https://www.albatcp.org/2021/06/30/antigua-barbudavacuna-sinopharm/

Arciniegas, Yurany, "Nicaragua recibe una donación de la dosis Sputnik V para comenzar a vacunar contra el covid-19", France 24, 24 de febrero de 2021, https://www.france24.com/es/\% C3\%Alfrica/20210224-covid19hoy-noticias-pandemia-vacuna cion-covax-francia-bolivia

Banco Mundial, "Clasificación de los países según nivel de renta", The World Bank, 2021, https://datahelpdesk.worldbank.org/ knowledgebase

Banco Mundial, "Población total”, The World Bank, 2021, https:// datos.bancomundial.org/indicador/SP.POP.TOTL

BELDYK, Mariano, "Alerta en Uruguay por la posible central nuclear flotante rusa en Argentina”, El Perfil, 16 de junio de 2021, 
https://www.perfil.com/noticias/actualidad/alerta-uruguayposible-central-nuclear-flotante-rusa-argentina.phtml

Bhutani Brig, Rajeev, "Geopolitics To Geo-Economics To... The New Era Of Geo-Technology”, India, Centre for Joint Warfare Studies, 2019, https://cenjows.in/upload_images/pdf/Inside_ GEOPOLITICS_10-5-19.pdf

BRIDGE, "China covid-19 Vaccine Tracker", 26 de julio de 2021, https://bridgebeijing.com/our-publications / our-publica tions-1/china-covid-19-vaccines-tracker/\#comment-2

Carman, Ezequiel y Joseph CARL, "A U.s. vaccine diplomacy strategy for Latin America and the Caribbean”, Global Americans, 15 de junio de 2021, https://theglobalamericans.org/2021/06/au-s-vaccine-diplomacy-strategy-for-latin-america-and-the-ca ribbean/

Cohen, Saul Bernard, Geopolitics: The geography of international relations, Londres, Rowman \& Littlefield, 2014.

"Colombia aplaude los avances en derechos humanos de China", El Tiempo, 24 de marzo de 2021, https://www.eltiempo.com/ politica/gobierno/colombia-aplaude-los-avances-en-dere chos-humanos-de-china-575906

"Córdoba firmó un acuerdo para comprar un millón de vacunas del laboratorio CanSino", INFOBAE, 14 de junio de 2021, https:// www.infobae.com/politica/2021/06/15/cordoba-firmo-unacuerdo-para-comprar-un-millon-de-vacunas-del-laboratoriocansino/

Corradini, Luisa, "Diplomacia de las vacunas: cómo Rusia y China se disputan al mundo en desarrollo", La Nación, 17 de enero de 2021, https://www.lanacion.com.ar/el-mundo/luisanid2572925/

Cox, Robert, Production, power and world order. Social forces in the making of history, Nueva York, Columbia University Press, 1987.

"El gobierno de Kicillof firmó un acuerdo para comprar 10 millones de dosis de vacunas Covaxin de un laboratorio de la India", IN FOBAE, 4 de junio de 2021, https://www.infobae.com/politica/2021/06/04/el-gobierno-de-kicillof-firmo-un-acuerdo-paracomprar-10-millones-de-dosis-de-vacunas-covaxin-de-un-labo ratorio-de-la-india/ 
FuINT, Colin, Introduction to geopolitics, Londres, Routledge, 2006.

Fulker, James, "92 low-and middle-income economies eligible to get access to COvid-19 vaccines through Gavi Covax AMC", Gavi, 31 de julio de 2020, https://www.gavi.org/news/mediaroom/92-low-middle-income-economies-eligible-access-co vid19-vaccines-gavi-covax-amc

GEREFFI, Gary, "Las cadenas productivas como marco analítico para la globalización”, Problemas del Desarrollo, Revista Latinoamericana de Economía, vol. 32, núm. 125, 2001, pp. 9-38.

GerefFi, Gary, "What does the Covid-19 pandemic teach us about global value chains? The case of medical supplies", Journal of International Business Policy, núm. 3, 2020, pp. 287-301.

Global Health Centre, "Covid-19 Vaccine Manufacturing Agreements", 3 de junio de 2021, Graduate Institute of International and Development Studies, https:/ /www.knowledgeportalia.org/ covid19-vaccine-manufacturing

Global Health Centre, "Covid-19 Vaccine Donations", Graduate Institute of International and Development Studies, 4 de junio de 2021, https://public.tableau.com/app/profile/global. health.center4838/viz/DonationsMaps_16227998507010/In dianSecArr

Gobierno de Estados Unidos, Departamento de Estado, "Secretary Anthony Blinken with Roula Khalaf of the Financial Times", 3 de mayo de 2021, https://www.state.gov/secretary-antony-jblinken-with-roula-khalaf-of-the-financial-times/

Gobierno de la India, Ministerio de Asunto Exteriores, "Vaccine Supply", 29 de mayo de 2021, https:/ /www.mea.gov.in/vacci ne-supply.htm

GonZÁlez-Vicente, Rubén, "The internationalization of the Chinese state”, Political Geography, vol. 30, núm. 7, 2011, pp.402-411.

Guetta-Jeanrenaud Lionel, Nicolas Poitiers y Reinhilde Veugel ERS, "A world divided: global vaccine trade and production", Bruegel [Blog], 20 de julio de 2021, https://www.bruegel. org/2021/07/a-world-divided-global-vaccine-trade-and-pro duction/ 
Harrison, Chase, “¿Qué es covax y qué significa para América Latina?”, As / COA Online, 7 de junio 2021, https:/ / www.as-coa. org/articles/que-es-covax-y-que-significa-para-america-latina

Harrison, Chase, "Tracker: u.s. Vaccine Donations to Latin America", As/cOA Online, 28 de julio de 2021, https:/ / www.as-coa. org/articles/tracker-us-vaccine-donations-latin-america

Hernández, Carlos, "El Comando Sur de Ee.uU. incrementará su presencia militar en America Latina”, Revista de Defensa y Seguridad en España y Latinoamérica, 15 de marzo de 2020, https:// www.infodefensa.com/latam/2020/03/15/noticia-comando -incrementara-presencia-militar-hemisferio.html

Hoffmann, Bert, "El Caribe, China y la geopolítica de las vacunas", Nueva Sociedad, abril de 2021, https://nuso.org/articulo/la-bendicion-del-caribe/

"Jujuy inició gestiones con China para comprar 1 millón de vacunas contra el coronavirus", INFOBAE, 20 de mayo de 2021, https:/ / www.infobae.com/politica/2021/05/20/jujuy-inicio-gestionescon-china-para-comprar-1-millon-de-vacunas-contra-el-coro navirus/

Karásková, Ivana y Veronika Blablova, "The Logic of China's Vaccine Diplomacy. An in-depth look at where China's vaccines are going hints at the motivations behind the campaign", The Diplomant, 24 de mayo de 2021, https:/ / thediplomat.com/ 2021/03/the-logic-of-chinas-vaccine-diplomacy/

Kiernan, Samantha, Serena Tohme, Kailey Shanks y Basia RosenBAUM, "The Politics of Vaccine Donation and Diplomacy. Is a friend in need a friend indeed?", Think Global Health, 4 de junio de 2021, https://www.thinkglobalhealth.org/article/ politics-vaccine-donation-and-diplomacy

LAING, Aislinn y Cassandra Garrison, "Amid scramble for covid-19 vaccine, Latin America turns to Russia”, Reuters, 1 de mayo de 2021, https://www.reuters.com/business/healthcare-pharma ceuticals / amid-scramble-covid-19-vaccine-latin-america-turnsrussia-2021-03-01/

LiAng, Haoguang y Zhang YaOJun, The theoretical system of Belt and Road Initiative, Luxemburgo, Springer, 2019. 
Mccarthy, Niall, "The Countries Dominating Covid-19 Vaccine Production”, Statista, 23 de marzo de 2021, https://www.statis ta.com/chart/24492/total-covid-19-vaccine-production-bycountry/

Morillas, Pol, "Multipolaridad sanitaria: el uso geopolítico de la vacuna”, СІDов, julio de 2021, https://www.cidob.org/articu los/cidob_report/n_7/multipolaridad_sanitaria_el_uso_ geopolitico_de_la_vacuna

Naciones Unidas, unesco, "Covid-19 y Vacunación en América Latina y el Caribe: desafío, necesidades y oportunidades", 4 de agosto de 2021, https://es.unesco.org/news/covid-19-y-vacu nacion-america-latina-y-caribe-desafios-necesidades-y-oportu nidades

Natarajan, Swaminathan, "China vs India: las claves para entender la larga disputa fronteriza que generó un enfrentamiento que dejó varios soldados muertos”, ввс World Services, 5 de junio de 2020, https://www.bbc.com/mundo/noticias-internacional-52871613

Palomino Uribe, Sammy Johan, "Venezuela firmó un contrato por 10 millones de vacunas EpiVacCorona contra la covid-19", Anadolu Agency, 5 de junio de 2021, https://www.aa.com.tr/ es/mundo/venezuela-firmó-un-contrato-por-10-millones-devacunas-epivaccorona-contra-la-covid-19/2264366

Palomino Uribe, Sammy Johan, "La vacuna Sputnik de una sola dosis se produciría en Bolivia”, Anadolu Agency, 15 de junio de 2021, https://www.aa.com.tr/es/mundo/la-vacuna-sputnik-deuna-sola-dosis-se-producir\%C3\%ADa-en-bolivia/2242592

Pandey, Munish Chandra, "India's donation of covid jabs to Dominica may help bring back Mehul Choksi”, India Today, 27 de mayo de 2021, https://www.indiatoday.in/india/story/india-dominica-mehul-choksi-covid-vaccines-1807579-2021-05-27

PoAst, Paul, "Does issue linkage work? Evidence from European alliance negotiations, 1860 to 1945", International Organization, vol. 66, núm. 2, 2012, pp. 277-310.

"Polémica en puerta: llegan a Uruguay las vacunas donadas a la Conmebol", La Voz, 28 de abril de 2021, https://www.lavoz. 
com.ar/deportes/futbol/polemica-en-puerta-llegan-a-uru guay-las-vacunas-donadas-a-la-conmebol/

"Qué provincias buscan comprar vacunas por su cuenta y con quién negocian", Cronista, 30 de mayo de 2021, https://www. cronista.com/economia-politica/mas-provincias-negocian-lacompra-de-dosis-para-acelerar-la-vacunacion/

Ruvalcaba, Daniel, "La política exterior de Joseph Biden hacia América Latina: un análisis prospectivo al inicio del nuevo gobierno", Revista Izquierdas, 2021, pp. 1-26.

"Santa Fe firmó un acuerdo para comprar un millón de vacunas CanSino", INFobae, 11 de junio de 2021, https:/ /www.infobae.com/ politica/2021/06/12/santa-fe-firmo-un-acuerdo-para-comprar -un-millon-de-vacunas-cansino/

"Sinovac evalúa producción de vacunas en Chile y anunció desarrollo de dosis contra variante Gamma", cNN Chile, 19 de julio de 2021, https://www.cnnchile.com/coronavirus/sinovac-eva lua-produccion-vacunas-chile-desarrollo-dosis-variante-gam ma_20210719/

"Sputnik V covid-19 vaccine", Statista Research Department, 24 de junio de 2021, https://www.statista.com/topics/7762/sputnikv-covid-19-vaccine/

Strange, Susan, "States, firms and diplomacy", International Affairs, vol. 68, núm. 1, 1992, pp. 1-15.

Tharoor, Sashi, "India’s Smart Vaccine Diplomacy", Project Syndicate, 11 de marzo de 2021, https:/ / www.project-syndicate.org/ commentary/india-covid19-vaccine-diplomacy-by-shashi-thar oor-2021-03

Tokatlian, Juan Gabriel, "Equidistancia y para-diplomacia”, Clarín, 13 de junio de 2021, https://www.clarin.com/opinion/equidis tancia-diplomacia_0_Zjly6EHYM.html

Tokatlian, Juan Gabriel, “No One's Supplanting U.S. Military Influence in Latin America", Defense One, 5 de septiembre de 2018, https://www.defenseone.com/ideas/2018/09/no-onessupplanting-us-military-influence-latin-america/151029/

Urdínez, Francisco, Fernando Mouron, Luis Schenoni y Amâncio de Oliveira, "Chinese economic statecraft and US hegemony 
in Latin America: an empirical analysis, 2003-2014", Latin American Politics and Society, vol. 58, núm. 4, 2016, pp. 3-30.

Vélez-Plickert, Marcela, "La lucha entre Ee.uU. y China por conquistar Latinoamérica con sus vacunas”, DFMAs, 4 de julio de 2021, https:/ / dfmas.df.cl/df-mas/glocal/la-lucha-entre-ee-uu-ychina-por-conquistar-latinoamerica-con-sus-vacunas 
